\title{
Teaching of Energy Issues: A Debate Proposal for a Global Reorientation
}

\author{
JOSEP LLUIS DOMÉNECH ${ }^{1}$, DANIEL GIL-PÉREZ ${ }^{2}$, ALBERT \\ GRAS-MARTII $^{1}$, JENARO GUISASOLA ${ }^{3}$, JOAQUÍN MARTÍNEZ- \\ TORREGROSA $^{1}$, JULIA SALINAS ${ }^{4}$, RICARDO TRUMPER ${ }^{5,7, *}$ \\ PABLO VALDÉS ${ }^{6}$ and AMPARO VILCHES ${ }^{2}$, \\ ${ }^{1}$ Universitat d'Alacant, Alacant, 03080, Spain; ${ }^{2}$ Universitat de València, València, Spain; \\ ${ }^{3}$ Euskal Herriko Unibersitatea, Universidad del País Vasco, Bilbao, Spain; ${ }^{4}$ Universidad \\ Nacional de Tucumán, Tucumán, Argentina; ${ }^{5}$ University of Haifa, Haifa, 31905, Israel; \\ ${ }^{6}$ Instituto Superior de Tecnologías y Ciencias Aplicadas, Ciudad Habana, Cuba; ${ }^{7}$ Kibbutz \\ Hahoterim, Doar Na Hof Hacarmel,30870, Israel (E-mail: rtrumper@research.haifa.ac.il)
}

\begin{abstract}
The growing awareness of serious difficulties in the learning of energy issues has produced a great deal of research, most of which is focused on specific conceptual aspects. In our opinion, the difficulties pointed out in the literature are interrelated and connected to other aspects (conceptual as well as procedural and axiological), which are not sufficiently taken into account in previous research. This paper aims to carry out a global analysis in order to avoid the more limited approaches that deal only with individual aspects. From this global analysis we have outlined 24 propositions that are put forward for debate to lay the foundations for a profound reorientation of the teaching of energy topics in upper high school courses, in order to facilitate a better scientific understanding of these topics, avoid many students' misconceptions and enhance awareness of the current situation of planetary emergency.
\end{abstract}

Key words: Teaching energy, debate proposal, global reorientation

\section{Introduction}

There is a general agreement among science teachers on the importance of choosing the teaching of energy as a focus of interest in the science curriculum, since this is a central idea which provides an important key to our understanding of the way things happen in the physical, biological and technological world (Driver \& Millar 1986).

Moreover, the slow and painstaking development of the concept of energy and the related concepts of heat and work is a marvellous example of how concepts and theories are built and evolve in science.

* This paper has been conceived as a contribution to the Decade of Education for Sustainable Development, established by the UN General Assembly for the period 2005-2014. 
Furthermore, energy issues have personal, social and environmental implications that may help to enhance students' interest in learning. Understanding these implications is necessary in order to make informed decisions concerning the current situation of planetary emergency (Bybee 1991). As a result of the seriousness of this situation, the United Nations has established a 'Decade of Education for Sustainable Development' from 2005 to 2014.

This agreement on the importance of a sound understanding of this field has been accompanied by growing awareness of the existence of serious learning difficulties, even among university students. This has stimulated a great amount of research and discussion about how to teach this field of knowledge.

Most of this research addressed specific conceptual aspects such as the confusion between force and energy, or the idea of energy as a substance (some kind of fuel) contained in objects, thanks to which changes may occur (Black \& Solomon 1983; Watts 1983; Brook \& Driver 1984; Brook 1986; Nicholls \& Ogborn 1993). These learning difficulties gave rise, in the 1980s, to a wide debate about how to introduce energy into the curriculum (Duit 1981, 1986; Sexl 1981; Warren 1982; Hicks 1983; Solomon 1985).

This research, and the innovation derived from it, was associated, in general, with the conceptual-change learning model (Posner et al. 1982; Driver \& Oldham 1985; Tobin et al. 1994; Duit 2004). This model proposed basically to elicit alternative conceptions and to create cognitive conflicts in pupils, generating dissatisfaction with their current ideas (Trumper 1997) and preparing them for the introduction of scientific conceptions.

The effectiveness of these conceptual-change strategies, compared to the simple transmission of knowledge, was supported by considerable research undertaken in different fields of science education. However, these also showed some limitations (Shuell 1987; White \& Gunstone 1989). For this reason, researchers in the field of science education began to question the 'reductionism' of the conceptual-change proposals (Gil-Pérez \& Carrascosa 1985; Hashweh 1986). Duschl and Gitomer (1991) criticized the hierarchical view of conceptual-change, which assumes that changes in central commitments to a theory of science bring simultaneous changes to other ontological, methodological and axiological commitments within the conceptual framework: "if we are to produce radical restructuring of concepts, the personal correlate of Kuhn's revolutionary science, then it seems that we must also teach the procedural knowledge involved" (Duschl and Gitomer 1991, p. 847).

In other words, it is necessary to pay attention to how students reason (Gil-Pérez \& Carrascosa 1985; DiSessa 1993).

It also began to be understood that the construction of knowledge has axiological commitments and, in sum, that we cannot ignore the strong links of the conceptual, procedural and axiological dimensions of science 
learning at all levels, including upper high school (Hodson 1992; National Research Council 1996; Gil-Pérez et al. 2002). This has made it possible to move away from the typical reductionism of the activities included in science teaching and the incorporation of aspects which give a more adequate view of science as an open and creative activity. An activity centered in a contextualized approach of problematic situations (Gil-Pérez et al. 2002) or, in other words, large context problems (Stinner 1995) - relevant to the construction of knowledge and/or the attainment of technological innovations, capable of satisfying human needs.

This teaching strategy, which transforms the conceptual-change learning model into a conceptual, procedural and axiological change model, aims basically to involve pupils, with the aid and orientation of the teacher, in an open and creative work, inspired in that of scientists and technicians, thus including essential aspects currently ignored in science education, such as the discussion of the possible interest and worthiness of studying the situations proposed in particular, taking into account the science-technology-society-envionment (STSE) implications, in order to make this study meaningful and prevent students from becoming immersed in the treatment of a situation without having had the opportunity to form a first motivating idea about it (Gil-Perez et al. 2002). In this way pupils, as members of the scientific community, will have the occasion to practice decisionmaking about undertaking (or not) a certain research or innovation (Aikenhead 1985).

From this perspective, which conceives science learning as an immersion in a scientific culture (Gil-Pérez \& Vilches 2005), that is to say, as a process of oriented research that enables students to participate in the (re)construction of scientific knowledge, we have assumed that the different learning difficulties concerning energy issues noted in the literature are interrelated and connected to other aspects - conceptual as well as procedural and axiological - that are not sufficiently taken into account. In other words, a satisfactory approach to this or any other field of knowledge, demands global treatment, avoiding approaches that deal with individual aspects and are therefore, less effective (Morin 1999). With this assumption as a guide, we have proceeded to carefully analyze the literature published on the learning and teaching of energy issues (including high school and university textbooks, papers published in science education journals, etc.) followed by an in-depth discussion about the many debatable points.

As a result, we have formulated 24 interrelated propositions that we attempt to justify in this paper. They are presented with the explicit aim of favouring the exchange of different points of view, in order to advance towards a possible consensus about how to orient the teaching of energy at 
upper high school. The discussion on what to do with younger pupils is not tackled in this paper: while some authors such as Warren (1982) maintain that the concept of energy should not be taught until students have attained a high abstract reasoning level, others, such as Solomon (1983) or Trumper (1993), hold that we should begin as soon as possible, at the primary level. These authors' papers may be consulted for a first approach to this important debate, but our study concentrates on what to do when we teach theoretical physics, where conceptual reductionism and decontextualized learning are generally - and, in our opinion, erroneously - accepted.

The paper is structured in seven closely related sections:

- interest and relevance of the study of energy;

- strategies for the tentative construction of scientific knowledge about energy issues;

- first approach to the meaning of energy;

- systemic and relative nature of energy;

- the meaning of work and heat and their relation to energy;

- conservation and transformation of energy;

- degradation of energy;

- conclusion and perspectives: towards a real understanding of this scientific domain.

\section{Interest and Relevance of the Study of Energy}

Among the many studies on high school pupils' alternative conceptions about energy issues (Pfundt \& Duit 1998; Duit 2004) or other learning difficulties, we have found very few contributions related to the interest and relevance of this field. In effect, as we have already indicated, research and teaching are centered, in general, on conceptual aspects, paying little attention to the STSE relationships (Solbes \& Vilches 1997), to such an extent that no effort is made to show the importance of the subject or to generate students' interest. However, concentrating almost exclusively on conceptual aspects transmits a limited view of science, which paradoxically, harms conceptual learning. Effectively, science education research has shown that 'Students develop their conceptual understanding and learn more about scientific inquiry by engaging in scientific inquiry, provided that there is sufficient opportunity for and support of reflection' (Hodson 1992, p. 551). A meaningful understanding of concepts requires overcoming conceptual reductionism and orienting science learning as an activity close to scientific research, which integrates conceptual, procedural and axiological dimensions (Gil-Pérez \& Carrascosa 1985; Duschl \& Gitomer 1991). Three propositions are outlined in accordance with these general considerations. 
(1) If one wants to stress the rational character of scientific knowledge, one must be aware of the problems that led to the introduction of the concepts of energy and the entire associated body of knowledge. Students (and teachers!) have to perceive that concepts are not introduced arbitrarily, but are constructions, of a tentative character, made with the purpose of solving 'problems' (Otero 1985; Burbules \& Linn 1991; Hodson 1992).

(2) It is useful to encourage pupils to discuss the interest of the problems dealt with and help them to understand the reasons why the scientific community has been interested in these problems.

These two propositions are clearly related, and they express basic elements in any scientific study. Both contribute to making this study meaningful and prevent pupils from finding themselves involved in the treatment of a situation without having had the possibility of thinking why they are working on it.

It is possible, for instance, to associate the study of energy with the discussion of changes undergone by matter: to know why these changes take place, how to favour them, whether or not there are limits as regards the changes that may occur, how to avoid those that are undesirable, etc. In particular, it is beneficial to discuss the possible environmental and social repercussions of the use of energy resources. This leads us to the last proposition of this section:

(3) Regard for STSE interactions has to be an essential aspect in teaching this and any other scientific field, if we want to avoid the transmission of a decontextualized, socially neutral view of science and to prepare citizens capable of understanding the world they live in and of adopting responsible and well-founded attitudes to scientific and technological developments and their possible consequences (National Research Council 1996; Gil-Pérez \& Vilches 2005).

In the specific case of energy, this means, among other things, reflecting on the human needs for energy resources; analyzing the problems associated with the use of the various energy resources (extraction, transport, residues, ...); studying machines as aids to facilitate changes - without forgetting the current debates about reduction in energy use, alternative energy sources, lack of equilibrium between developed and underdeveloped countries, that are associated to the situation of planetary emergency (Gil-Pérez et al. 2003; Vilches \& Gil-Pérez 2003).

Naturally, we cannot impose a particular view in questions that have been and continue to be debated, but we must not disregard - as is normally the case - the role of this axiological dimension in scientific work. In the next section we refer to other dimensions (procedural and epistemological) of scientific work that should also be taken into account. 


\section{Strategies for the Tentative Construction of Scientific Knowledge about Energy Issues}

If pupils are to stop conceiving science as a dogmatic body of knowledge, which is often incomprehensible and often generates a lack of interest and even rejection, it is necessary to involve them in the (re)construction of this knowledge. This is the gist of the following propositions:

(4) Knowledge should not be directly presented in its final form as something to be accepted. On the contrary, we should guide the students to follow, to a certain extent, the process of construction of knowledge, enhancing the open and tentative nature of this process (Duschl 1990; Hodson 1992; Gil-Pérez et al. 2002). Doing this, pupils may follow the historical development of knowledge about energy (Bècu-Robinault \& Tiberghien 1998) and understand the hazy origin of the concepts and the close links between scientific and technical work, so frequently ignored (De Berg 1997; Kuhn 1977).

(5) This also means that students must have the opportunity to use strategies of elaboration and criteria of validation which are characteristic of scientific work (namely, to make assumptions, conceive experimental designs, etc.) and then compare their tentative constructions with those of the scientific community (Driver et al. 2000; Gil-Pérez et al. 2002). In this way pupils can become acquainted with the scientific criteria that led to the acceptance and later transformation of different energy conceptions, without ignoring the difficulties encountered (which are quite similar to some of these met by pupils themselves). It is useful to know the caloric theory (which conceived heat as a substance, so close to their own conceptions) and how and why it was later rejected, on establishing the relationship between mechanics and heat.

(6) It is necessary to stress the search for generality and global coherence that characterizes scientific endeavour, which allows the integration of apparently unconnected fields. Pupils should particularly understand that the integration of mechanics and heat was a profound scientific revolution, which made possible an understanding of the nature of heat and the establishment of the principle of energy conservation and transformation (Harman 1982; Kuhn 1977). It is also necessary to emphasize the universal validity of this principle - applicable to processes of any nature, at both macroscopic and microscopic level - which became, for this reason, one of the major milestones in the establishment of the unity of matter (Arons 1997).

In short, to make an adequate understanding of this or any other field of knowledge possible, it is necessary to consider, from the beginning of the study and throughout the whole process, axiological and procedural aspects such as those contemplated here, without falling into distorted and 
inefficient conceptual reductionisms. In this way pupils may achieve a sound and fruitful understanding of the meaning of concepts.

\section{First Approach to the Meaning of Energy}

Many studies have shown pupils' serious misunderstandings of the nature of energy (Watts 1983; Brook 1986; Nicholls \& Ogborn 1993; Pfundt \& Duit 1998), and this has generated keen debates on how to define this concept. Some authors have proposed beginning by conceptualising energy as a kind of quasi-material substance that participates in any process taking place around us. Duit (1987) affirms that this conception basically coincides with its everyday meaning, which facilitates pupils' learning. Nonetheless, as Duit himself points out, this definition becomes an obstacle to the learning of the scientific conception.

Contrary to what Warren (1982) calls the materialist view of energy as 'a substance, something of the nature of a pervasive fluid, which has objective existence' (p. 295), he asserts that 'teachers of physics should eliminate the word energy entirely from elementary teaching and should in more advanced work teach the scientific concept of energy, firmly based on the concept of work' (p. 297). It should be introduced as 'an abstract idea invented by scientists to help in the quantitative investigation of phenomena. It is defined as capacity for doing work' (Warren 1982, p. 295). This conception of energy 'as capacity for doing work', whose origin goes back to the 17th century (Trumper 1990), was still used by many 19th century scientists such as Maxwell (1877). However, when the Second Law of Thermodynamics was established, it became clear that not all energy is able to perform work. For this reason, Planck predicted at the beginning of the 20 th century that the traditional way of introducing energy in association with the concept of work would disappear in about twenty years (Duit 1986). Now we know that he was wrong: successive analyses of physics textbooks have shown that most of them still introduce the concept of energy as the capacity to do work (Lehrman 1973; Hicks 1983; Duit 1986; Doménech et al. 2001), in spite of the many disadvantages of this definition (Sexl 1981; Hicks 1983; Trumper 1990). For instance, Sexl (1981) states that this definition is not useful in thermodynamics, because 'the internal energy of a system cannot be transformed completely into work' (p. 287). Duit (1986) insists that this definition is only valid in mechanics; therefore, when pupils approach non-mechanical phenomena (e.g., chemical reactions) they will apply an inadequate conception of energy.

In an attempt to overcome these obstacles, it has been suggested that energy should be defined in a more general way, as the capacity to produce changes (Rogers 1965; Chisholm 1992; Arons 1997; Bunge 1999). 
This definition has also been criticized, because what makes a process take place is not related to variations of energy but to an increase of entropy (Gailiunas 1988; Resnick et al., 1992).

None of the above approaches seems completely acceptable because all of them have disadvantages. This has given rise to serious debate (Warren 1982; Duit 1986; Trumper 1990; Prideaux 1995). Perhaps for this reason many authors have decided to introduce energy just in an operational way (Trumper 1991). Feynman et al. (1963), for instance, affirm that it is important to realize that in physics we do not know what energy is, but we do have formulae to calculate certain numerical quantities, and when we add all of them up we always obtain the same result. In the same direction, Shadmi (1984) proposes basing the teaching of energy on the conservation principle, putting aside qualitative considerations. Hicks (1983) warns against the use, even as an initial definition, of the idea of energy as the capacity to produce work, because it is so short and easy to memorize that pupils may continue using it even after its limitations have been shown. For this reason Hicks proposes to avoid any qualitative definition of energy.

In our opinion, these merely operational introductions are inadequate for several reasons. First, this does not prevent the formation of distorted qualitative views, or the persistence of naïve conceptions acquired by environmental impregnation, regardless of any formal education (Gil-Pérez et al. 2002).

Second, pupils need to know that scientists do think qualitatively: before they begin to calculate, they already have the course of their reasoning in their minds. This, in most cases, can be expressed in simple words. Calculus and formulae are the next step. Directly introducing the quantitative treatment transmits a distorted and impoverished view of science that obstructs the knowledge construction process and generates inhibition and rejection.

Finally, we stress that the initial qualitative considerations about energy should not be judged in light of the body of knowledge accepted today (after much development), but in light of their capacity to facilitate the construction process, during which the initial ideas will evolve to more elaborated and fruitful conceptions. In a nutshell the point is not to look for a 'correct' conception as a starting point, but to accept that knowledge is a tentative, necessarily evolving, construction. The construction of meanings has to be conceived as the result of successive approaches, without renouncing the basic requirement of meaningfulness in each stage. The following propositions seek to express this two-fold necessity:

(7) The transformations that a system undergoes are due to interactions with other systems or to interactions among its parts; in other words, they are due to the capacity of matter to interact in different ways (Arons 1997). 
It is not a question of starting to define energy, but rather of approaching the problem of changes, explaining them as the product of interactions. A first qualitative idea of energy can be introduced afterwards.

(8) The idea of energy may be associated qualitatively with the configurations of systems and with the interactions that they allow. For example, the wind has energy because the particles in air can strike a windmill's sails and make them turn against friction (Resnick et al. 1992). In this way, as stated in the next proposition, energy is not deemed to be a physical fluid.

(9) Energy is not a kind of fuel needed to produce transformations, as students often conceive it (Ogborn 1986; McClelland 1989; Trumper 1993), but a capacity of transformation determined by the configuration of the intervening systems and by the properties of matter responsible for interactions. It is the specific reference to the interactions and to the configuration of a given system (e.g., a stone and the Earth) that explains why such a system may undergo or produce transformations, overcoming the conceptions of energy as a fluid or a fuel.

(10) In accordance with the above propositions, energy may be conceived, in a first approximation, as the capacity to produce transformations (Chisholm 1992; Arons 1997). Hence, transformations in the configurations of systems can be associated with variations in the energy of these systems (Trumper 1993).

(11) One may introduce various forms of energy (kinetic, gravitational potential, etc.) associated with various configurations of the system and with different forms of interactions. In other words, the diversity of qualifications that usually accompany the word energy indicates the property or properties of the system that will (or may) act in a certain process, or even the type of process in which the system will participate (Arons 1989; Resnick et al. 1992; Kaper \& Goedhart 2002). For example, a battery has electric energy because the separation of electric charges of different signs in the battery poles provides the system with the capacity to produce transformations when the circulation of charges is allowed.

The above propositions constitute initial approximations to the concept of energy that are meaningful and useful to begin the study of transformations, although further studies will oblige us to enrich and modify these initial conceptions. Some of these enrichments and modifications, whose global comprehension is essential to prevent pupils from remaining prisoners of alternative conceptions, are referred to in the following section.

\section{The Systemic and Relative Nature of Energy}

Several studies have shown that most pupils attribute energy to specific bodies and not to the system formed by the ensemble of objects which 
interact (Bauman 1992; Mallinckrodt \& Leff 1992; Van Huis \& Van den Berg 1993; Arons 1997; Van Heuvelen \& Zou 2001). The next proposition deals with this misconception.

(12) Energy is a property of systems, and speaking about the energy of an isolated object lacks scientific meaning. When, for instance, we speak about the gravitational potential energy of a stone, we know that it is due to the interaction between the stone and the Earth, and that therefore this energy belongs to the system formed by the two of them, not only to the stone (Bauman 1992; Resnick et al. 1992; Arons 1997). If we consider a body that is isolated, far enough from others to make gravitational interaction negligible, it is obvious that we cannot speak of gravitational energy. As Mallinckrodt and Leff (1992) state, potential energy always appears in the context of a pair (or ensemble) of objects that interact. There is no reason to attribute it solely to any of the objects.

All the studies we have found on pupils' misconceptions in relation to the systemic character of energy refer to potential energies. We have not found any reference to similar considerations about kinetic energy. On the contrary, even university textbooks always refer to the kinetic energy of an object, without explaining that this energy expresses the capacity of this object to interact with other objects, because it is moving towards them with a certain speed. In short, we deem kinetic energy to also be a property of the system formed by objects that can interact among themselves.

We stress the importance of clarifying the systemic character of kinetic energy, because this aspect is not dealt with in the literature and it is not easily accepted: its discussion even provokes initial rejection among teachers and even university professors.

To overcome the conception of energy as a physical fluid that objects possess, it is necessary to carry out a qualitative analysis of the processes that take place during the transformations undergone by a system. This makes the systemic character of energy clear in all cases and allows one to overcome a second obstacle: the notion of absolute values of energy.

(13) It is meaningless to speak of the energy of a system in absolute terms: we can only determine its variations when a certain process takes place. This is something generally pointed out in the literature (Beynon 1990; Chisholm 1992; Prideaux 1995), although the frequent use of relative values (corresponding to arbitrarily assigning zero energy to a certain configuration of the system) may mislead pupils, who take these relative values as absolute, unless we insist sufficiently on the relative character of the quantities used. This is important because the misconception of absolute values reinforces the interpretation of energy as something possessed by the objects themselves. 
The difficulties faced by pupils (and teachers!) when trying to understand and meaningfully use the concept of energy affect the related concepts of work and heat. The meaning of both concepts and their relation to energy is discussed in the following section.

\section{The Meaning of Work and Heat and their Relation to Energy}

The large number of papers about how to introduce the concepts of work and heat is indicative of the existence of serious learning difficulties in both cases. Accordingly, some authors have proposed not to use them and instead just speak about energy exchanges between the system and its surroundings (Kemp 1984; Barrow 1988). This approach hides the mechanisms by which the energy of a system changes, thereby rendering the comprehension of the transformations difficult (Mallinckrodt \& Leff 1992; Van Roon et al. 1994; Alonso \& Finn 1997). It is essential, for this reason, to pay attention to the meaning of these concepts, avoiding purely operational treatment. One cannot, for instance, define work just as the product of force and distance. This approach might favour a dogmatic view of science that distorts its tentative character: concepts are hypothetical inventions that have their origin in qualitative considerations.

The next two propositions aim to introduce both concepts (work and heat) coherent with this tentative, meaningful and evolutionary character of the scientific construction of knowledge.

(14) Qualitatively work may be conceived as the act of transforming matter by applying forces. This is the conception proposed by Maxwell (1877) and it reflects the idea of work in everyday life: any elementary example of what is considered work (digging the ground, lifting heavy objects, etc.) appears as a process of transformation of matter by means of forces. The operational definition of work as the product of force and distance corresponds to this qualitative idea for the simplest case of an object that is moved.

On the other hand, as energy is conceived as the capacity to cause change (see Proposition 10), work - that is to say, a process of changing matter by means of forces - may be related to variations of energy or, more precisely, to interchanges of energy between different systems or among parts of the same system. This allows us to conceive work as a form of energy exchange, in other words, of modifying the configurations of the parts of the system that interact (as we stated in Propositions 8-10).

Difficulties associated with the construction of the concept of heat have been even bigger than in the case of work, and they include the confusion between heat and temperature, the conception of heat as a material fluid which corresponds historically to the caloric theory - or the current 
interpretation of heat as a form of energy (Tarsitani \& Vicentini 1991; Bauman 1992; Alonso \& Finn 1995; Arons 1999). These ideas must not be simply rejected as errors, but positively valued as part of the construction process of the current conception of heat. In this process, a serious difficulty was the endless 'extraction' of the caloric 'contained' in an object, when one strikes or rubs it. This and other difficulties led to the hypothesis of the equivalence between heat $Q$ and work $W$, taking into consideration the microscopic interactions occurring in the system, namely, accepting the corpuscular conceptions on the nature of matter. As Alonso and Finn (1969, chapter 9) explain, ' $Q$ is composed of a sum of a very large number of very small individual external works, which are such that they cannot be expressed collectively as an average force times an average distance'. (p. 263). The concept of 'internal energy' can be introduced similarly (Arons 1999). Therefore, the following proposition may be formulated:

(15) From the kinetic-molecular theory, heat arises as a statistical magnitude which aggregates a large number of very small works performed at a microscopic level. Therefore, heat, like macroscopic work, is not a form of energy but rather a mechanism of exchange of energy between the particles of the system and the surroundings (Atkins 1984; Tarsitani \& Vicentini 1991; Alonso \& Finn 1995; Arons 1997). An exchange that, in the case of heat, takes place when systems at different temperatures (i.e., systems whose particles have different average energies) are put together and their particles interact. The energy of the ensemble of particles of the system may be included in the concept of internal energy.

Heat, therefore, is neither a substance (caloric) nor a form of energy, as is frequently said even in textbooks (Doménech et al. 2001). A system does not have heat in the same sense that it does not have work.

It is not correct, for instance, to speak about the conversion of kinetic energy into heat when one describes what happens when a car stops: this should be described as transformation of kinetic energy into internal energy (Arons 1999). Actually, it is not a problem of words but of interpretation: When, for instance, someone talks about a 'sunrise', this is understood to happen because the Earth is spinning around its axis. In the same way we can keep saying that 'the wheels got hot', but it must be understood that this means that the internal energy of the wheels (and that of the surroundings) increased. As Solomon (1983) writes,

pupils must never lose the ability to communicate. It would indeed be a poor return for our science lessons if they could no longer comprehend remarks like 'wool is warm' or 'we are using up all our energy'. What we are asking from our pupils, then, is that they should be capable to think and operate in two different domains of knowledge and be capable of distinguishing between them (Solomon 1983, p. 50). 
It is also necessary to avoid the frequent error of conceiving internal energy as a magnitude that includes exclusively the kinetic energy of the particles (Besson 1999). That would be true in the case of perfect gases, whose particles are not linked, but in other cases the continuous interactions that take place at microscopic level make the kinetic and potential energy of the particles inseparable. Thus, internal energy embraces both the kinetic and potential energy of the ensemble of particles.

As we can see, advances made in the understanding of energy, work, and heat were related to the corpuscular theory (Ellse 1988; Arons 1989; Bauman 1992; Koliopoulos \& Ravanis 1998; Kaper \& Goedhart 2002). These advances led to the integration of mechanics and heat, two branches of science that had developed autonomously and seemed to have nothing in common (see Proposition 6). This integration, associated with the works of Carnot, Rumford, Joule, Thomson, Mayer, etc., made it possible to establish the law of conservation of energy and better explain the causes of transformations. We shall approach these questions in the final two sections.

\section{Conservation and Transformation of Energy}

Several authors have pointed out that the current conception of energy emerged when its conservation was established, thanks to the comprehension of the role played by the interactions at a microscopic level between a system and its surroundings and the consequent integration of mechanics and heat (Bècu-Robinault \& Tiberghien 1998; Goldring \& Osborne 1994; Trumper 1990). Accordingly, this proposition may be enunciated:

(16) A variation of energy in a system, $\Delta E$, may be due to exchanges with other systems at a macroscopic level (work) or at a microscopic level (heat). So we can write $W+Q=\Delta E$, where $W$ represents the work performed by forces external to the system and $Q$ encompasses the microscopic works done when the system is in contact with surroundings at a different temperature. This expression $W+Q=\Delta E$, which was advanced as a daring hypothesis that integrated mechanics and heat, received empirical support and became the 'first law of thermodynamics'. This law implicitly affirms the conservation of energy when a system remains isolated, although certain forms of the energy of the system may change into other forms. This may be expressed in the following way:

(17) The changes a system undergoes may involve the transformation of some kinds of energy into other forms of energy (for instance, gravitational potential into kinetic), or the transfer of energy from some systems to other systems, or from some parts of a system to other parts of the same system (as happens when objects at different temperatures are brought into contact with each other). However, there is a restriction to 
the possible transformations: only changes in the properties that make the total energy of an isolated system (including internal energy) remains constant can happen.

Some textbooks present the conservation of energy as a generalization of the conservation of the so-called mechanical energy that occurs in some transformations, for instance, the free fall of a stone (with the help of Newton's second law, it can be demonstrated, that during a free fall $\Delta E_{k}+\Delta E_{p}=0$ ). However the conservation of energy in all processes cannot be derived from the laws of dynamics and it is an independent statement (Arons 1999). The establishment of the law of conservation required, as explained, awareness of the interactions at a microscopic level and the associated forms of internal energy. This was only possible when the relationship between mechanical and thermal effects was understood (Alonso \& Finn 1969). One cannot therefore accept attempts to present the principle of conservation of energy as a generalization of the work-energy relationships established in mechanics. This confusion, which shows an inadequate understanding of the law of conservation of energy, has been widely discussed in science education (Sherwood 1983; Bernard 1984; Sherwood \& Bernard 1984; Arons 1989, 1999; Mallinckrodt \& Leff 1992; Bauman 1992; Leff \& Mallinckrodt 1993; Van Heuvelen \& Zou 2001).

Another confusing aspect that has not received as much attention is the consideration of $W+Q=\Delta E$ as a general expression of the conservation of energy that is always valid. Instead, it should be noted that:

(18) Energy variations may take place, not only through work or heat, but also by means of other processes, such as radiation exchange (Chabay and Sherwood 1999, p. 149). Astonishingly, this aspect is rarely contemplated in high school courses and science education research. Although we agree that the study of radiation, as a mechanism of energy transfer, should not be fully developed at this level, given its complexity, it is absolutely necessary to make qualitative references to this process. It cannot be forgotten that most of the energy resources available on Earth (including fossil fuels) have their origin in solar radiation; neither can it be ignored that gaining a grasp of the greenhouse effect is not possible without reference to exchanges of energy by radiation. It is therefore necessary to state that the first law of thermodynamics, in the form $W+Q=\Delta E$ is not always applicable, although the conservation of energy in an isolated system remains a valid statement.

The conservation of energy has led some authors to question the idea of energy as a 'capacity to produce changes' (Duit 1986; Ogborn 1986; Pintó 1991). According to Ogborn (1986), the total energy remains constant whatever the process, so changes in energy cannot be the reason for a process to happen. It is important to discuss this conclusion. This is the aim of the following proposition. 
(19) Although the total energy of an isolated system remains constant, whenever such a system experiences irreversible changes energy transfers and/or transformations of energy take place in its interior. Expressions such as $E=$ constant or $\Delta E=0$ seem to indicate that energy is not related to transformations, but $\Delta E=0$ encompasses a set of variations of energy that have to be made explicit:

$$
\Delta E_{k}+\Delta E_{p \text { gravitational }}+\Delta \mathrm{E}_{p \text { electric }}+\cdots=0
$$

This justifies the usual association of energy and change, although this association does not explain in itself which sequence of changes are possible and which are not; it also demands that attention be paid to the energy 'degradation' that accompanies any process.

\section{Degradation of Energy}

As Duit (1986) states,

No other aspect in physics instruction is treated in such disproportion to its significance. Without the aspect of energy degradation, understanding of the physical energy concept is incomplete; without it the energy concept must fail in applications to nature, technology and everyday life (Duit 1986, p. 89).

However, it is not difficult to approach this essential characteristic of energy qualitatively:

(20) As a result of the interactions and consequent transformations of a system, energy degrades or, in other words, is distributed more homogeneously. In other words, isolated systems evolve towards more disordered states, of a larger probability: the many particles in a system are more likely to move randomly than in an orderly fashion. This evolution towards more disordered configurations reduces the possibility of further transformations of the system (Atkins 1984; Duit 1986; Ogborn 1990). For this reason, a new magnitude - 'entropy' $S$ - is introduced as a measure of the 'disorder' of the system, of energy degradation. This magnitude is defined in such a form that, in an isolated system, every irreversible process that takes place increases its entropy (while the total energy of the system remains constant) and this increase diminishes the probability of subsequent changes. These ideas can be understood by pupils without too many difficulties: they understand, for instance, that it is easy to transform all the kinetic energy of a system into internal energy (for instance, when a car stops), while the reciprocal process is much less efficient, because it is highly improbable to completely transform the random agitation of the large number of particles that make up a system into a synchronized movement of all of them in the same direction (Frish \& Timoreva 1972; 
Atkins 1984). It is true that in many open systems (such as living beings) the entropy decreases (systems become more ordered), but the total entropy of the isolated system formed by these living beings and its surroundings increases.

The comprehension of these processes of degradation or homogenization of energy (increase of entropy) provides a clear explanation of the apparent contradiction between expressions such as 'energy crisis' or 'energy depletion' and the law of conservation of energy:

(21) Expressions such as 'energy consumption' or 'energy crisis', do not mean, that energy disappears but that it is no longer useful (the new configuration of the system does not facilitate other changes to occur). Therefore, the apparent contradiction between 'energy conservation' and the 'need for energy resources', disappears (Duit 1986; Ogborn 1990).

(22) The process of energy distribution (or the increase in entropy) of a system reduces the probability of that system undergoing further macroscopic transformations. It is necessary to insist on this point (one that has not been dealt with in science education literature), because the interactions (and therefore, the transformations) keep on occurring at a microscopic level. However, what is really quite unlikely (although not impossible) is that macroscopic transformations occur which lead to more 'ordered' configurations.

This section on energy degradation may be summed up by one last proposition:

(23) Two conditions have to be met in changes that an isolated system may experience:

- Transformations of energy and/or energy transfers between parts of the system must necessarily satisfy the principle of energy conservation.

- Initially energy cannot be uniformly distributed. The system evolves towards configurations globally more uniform (of greater entropy), although the entropy of some parts of the system may decrease.

Now pupils can understand that initial definitions of energy, such as 'capacity for performing work' or 'capacity for producing changes' are not generally valid; we need another concept (entropy) to determine the possibility of producing these changes. And they may well also understand, more importantly, that scientific concepts evolve.

These are some of the key ideas that have to be learned in order to achieve a sound conceptual comprehension of this basic area of physics. However, it must be emphasized that a fair scientific knowledge cannot be limited to conceptual aspects; it must also incorporate procedural and axiological aspects like those introduced in the first two sections. Moreover, students are not expected to attain a correct conceptual understanding 
without taking into consideration such aspects. This central idea is developed in the last section of our paper.

\section{Conclusion and Perspectives: Towards a Real Apprehension of this Scientific Domain}

Proper learning of scientific knowledge implies, among other things, the capacity to use the new concepts in the resolution of problems and in the qualitative interpretation of different situations (corresponding, for instance, to questions concerning everyday phenomena). In the case of energy and associated concepts, it is necessary, in particular, to overcome students' tendency to disregard the use of the energy approach in solving problems of motion, and to use only the kinematics-dynamic approach (Driver \& Warrington 1985; McDermott 1993; Doménech et al. 2001).

However, it is not a question of regretting 'pupils' tendency' to ignore the energy approach. The important thing is to realize that it is necessary to give pupils more opportunities for using the new knowledge (not only the new concepts!) in a variety of situations, and so overcome the usual conceptual reductionism:

(24) A meaningful appropriation of this field of knowledge demands several specific actions:

- To put special emphasis on the STSE relationship. This should include the construction of scientific and technological products (engines, solar generators, ...), thus overcoming excessively bookish approaches, as well as the discussion of the close relationship of energy issues (its role in our lives, problems associated with obtaining and using energy resources...) with the current situation of planetary emergency (Gil-Pérez et al. 2003).

- To show the coherence of the new knowledge with other scientific areas, thereby favouring alternative approaches and syntheses.

- To foster pupils' ability to conceive new problematic situations, thereby avoiding any impression of dealing with a finished and closed body of knowledge, and awakening interest in further developments.

This set of 24 propositions attempts to offer a global view of what we consider an adequate 'initial' comprehension of energy issues at high school. Our basic assumption is that the above propositions are mutually interdependent and cannot be addressed separately. In other words, we consider that the student difficulties pointed out by numerous researchers may be due to the fact that usual teaching practice does not pay attention to a good number of the aspects that have been discussed above. For this reason, we consider that an in-depth discussion is necessary to better orient the teaching of this fundamental domain, in order to avoid the current 
mere operational treatments and integrate the conceptual, procedural and axiological dimensions.

In this respect, it is commonly argued that preparing specialists in biology, physics and chemistry necessitates an approach focused on the concepts, principles and laws of these disciplines. At the same time, science education for responsible citizenship (with its emphasis on STSE issues and the development of critical awareness) is seen as an alternative form of education for non-specialists. The pursuit of citizens' education instead of the training of future scientists generates considerable opposition among those who argue, legitimately, that society needs scientists and technicians. Why can't we do both? It is our contention that a science education focussed exclusively on the conceptual dimension is equally negative for the education of future scientists and technicians (Gil-Pérez \& Vilches 2005). As we have already pointed out, this orientation transmits a distorted and impoverished view of science that not only diminishes the interest of young people in scientific careers (Matthews 1991; Solbes \& Vilches 1997) but negatively affects conceptual learning. Together with Hodson, we contend that 'students develop their conceptual understanding and learn more about scientific inquiry by engaging in scientific inquiry, provided that there is sufficient opportunity for and support of reflection' (Hodson 1992, p. 551). If we are to achieve a meaningful understanding of concepts and theories, we must reorganize science learning into an activity that integrates conceptual, procedural and axiological dimensions (Duschl $\&$ Gitomer 1991). This paves the way for a more creative, open and socially contextualized view of science, in accordance with the real tentative nature of techno-scientific activities, in which critical awareness and questioning of what seems 'natural' and 'obvious' plays an essential role. This is the basic aim of our study and the subsequent proposals.

\section{References}

Aikenhead, G.S.: 1985, 'Collective Decision-making in the Social Context of Science', Science Education 69(4), 453-475.

Alonso, M. \& Finn, E.: 1969, Fundamental University Physics I Mechanics and Thermodynamics, 2nd edn, Addison-Wesley, Reading, MA.

Alonso, M. \& Finn, E.: 1995, 'An Integrated Approach to Thermodynamics in the Introductory Physics Course', The Physics Teacher 33, 296-310.

Alonso, M. \& Finn, E.: 1997, 'On the Notion of Internal Energy', Physics Education 32(4), $256-264$.

Arons, A.B.: 1989, 'Developing the Energy Concepts in Introductory Physics', The Physics Teacher 27, 506-517.

Arons, A.B.: 1997, Teaching in Introductory Physics, John Wiley \& Sons, Inc, New York. 
Arons, A.B.: 1999, 'Development of Energy Concepts in Introductory Physics Courses', American Journal of Physics 67(12), 1063-1067.

Atkins, P.W.: 1984, The Second Law, Scientific American Books, Inc., New York.

Barrow, G.M.: 1988, 'Thermodynamic should be Built on Energy - not on Heat and Work', Journal of Chemical Education 65(2), 122-125.

Bauman, R.P.: 1992, 'Physics that Textbook Writers Usually get Wrong', The Physics Teacher 30, 264-269.

Bècu-Robinault, K. \& Tiberghien, A.: 1998, 'Integrating Experiments into the Teaching of Energy', International Journal of Science Education 20(1), 99-114.

Bernard, W.H.: 1984, 'Internal Work: A Misinterpretation', American Journal of Physics 52(3), 253-254.

Besson, U.: 1999, 'Bilan énergétiques: une mise au point conceptuelle', Bulletin de L'Union des Physiciens 93(812), 383-405.

Beynon, J.: 1990, 'Some Myths Surrounding Energy', Physics Education 25, 314-316.

Black, P. \& Solomon, J.: 1983, 'Life-world and science world-pupils' ideas about energy', in Entropy in the School, vol. 1, Roland Eotvos Physical Society, Budapest.

Brook, A.: 1986, 'Children's Understanding of Ideas about Energy: A Review of the Literature', in Driver R. \& Millar R. (eds) Energy Matters, University of Leeds, Leeds, pp. $33-45$.

Brook, A. \& Driver, R.: 1984, Aspects of Secondary Students' Understanding of Energy, Children's Learning Science Project, University of Leeds, Leeds.

Bunge, M.: 1999, 'La energía entre la física y la metafísica', Revista de Enseñanza de la Física 12(1), 53-56 (See also, 'Energy: Between Physics and Metaphysics', Science \& Education 2000, 9(5), 457-461).

Burbules, N. \& Linn, M.: 1991, 'Science Education and Philosophy of Science: Congruence or Contradiction', International Journal of Science Education 13(3), 227-241.

Bybee, R.W.: 1991, 'Planet Earth in Crisis: How should Science Educators Respond?', The American Biology Teacher 53(3), 146-153.

Chabay, R.W. \& Sherwood, B.A.: 1999, Matter \& Interactions, (Preliminary Edition), John Wiley \& Sons, Inc, New York.

Chisholm, D.: 1992, 'Some Energetic Thoughts', Physics Education 27, 215-220.

De Berg, K.C.: 1997, 'The Development of the Concept of Work: A Case where History can Inform Pedagogy', Science \& Education 6, 511-527.

DiSessa, A.: 1993, 'Toward an Epistemology of Physics', Cognition and Instruction 10, $105-225$.

Doménech, J.L., Gil-Pérez, D., Gras, A., Guisasola, J., Martínez-Torregrosa, J. \& Salinas, J.: 2001, 'La enseñanza de la energía en la educación secundaria:. Un análisis crítico', Revista de Enseñanza de la Física 14(1), 45-60.

Driver, R. \& Millar, R.: 1986, 'Teaching Energy in Schools: Towards an Analysis of Curriculum Approaches', in Driver R. \& Millar R. (eds) Energy Matters, University of Leeds, Leeds, pp. 9-24.

Driver, R., Newton, P. \& Osborne, J.: 2000, 'Establishing the Norms of Scientific Argumentation in Classrooms', Science Education 84(3), 287-312.

Driver, R. \& Oldham, V.: 1985, 'A Constructivist Approach to Curriculum Development in Science', Studies in Science Education 13, 105-122.

Driver, R. \& Warrington, L.: 1985, 'Students Use of the Principle of Energy Conservation in Problem Situations', Physics Education 20, 171-176.

Duit, R.: 1981, 'Understanding Energy as a Conserved Quantity', European Journal of Science Education 3(3), 291-301. 
Duit, R.: 1986, 'In Search of an Energy Concept', in Driver R. \& Millar R. (eds) Energy Matters, University of Leeds, Leeds, pp. 67-101.

Duit, R.: 1987, 'Should Energy be Illustrated as Something Quasi-material?', International Journal of Science Education 9, 139-145.

Duit, R.: 2004, Bibliography: Students' and Teachers' Conceptions and Science Education (STCSE), IPN, Kiel. Available on line: http://www.ipn.uni-kiel.de/aktuell/stcse/ stcse.html.

Duschl, R.A.: 1990, Restructuring Science Education: The importance of Theories and Their Development, Teachers College, Columbia University, New York.

Duschl, R.A. \& Gitomer, D.H.: 1991, 'Epistemological Perspectives on Conceptual-Change: Implications for Educational Practice', Journal of Research in Science Teaching 28(9), 839-858.

Ellse, M.: 1988, ‘Transferring not Transforming Energy', School Science Review 69, 427-437.

Feynman, R.P., Leighton, R.B. \& Sands, M.: 1963, The Feynman Lectures on Physics, Mainly Mechanics, Radiation and Heat vol. I, Addison-Wesley, Reading, MA.

Frish S. \& Timoreva A.: 1972, Curso de Física General, Vol. I, Ed. Mir., Moscú.

Gailiunas, P.: 1988, 'Is Energy a Thing? Some Misleading Aspects of Scientific Language', School Science Review 69, 587-590.

Gil-Pérez, D. \& Carrascosa, J.: 1985, 'Science Learning as a Conceptual and Methodological Change', European Journal of Science Education 7(3), 231-236.

Gil-Pérez, D., Guisasola, J., Moreno, A., Cachapuz, A., Pessoa, A., Martínez-Torregrosa, J., Salinas, J., Valdés, P., Gónzález, E., Gené, A., Dumas-Carré, A., Tricárico, H. \& Gallego, R.: 2002, 'Defending Constructivism in Science Education', Science \& Education 11, 557-571.

Gil-Pérez, D. \& Vilches, A.: 2005, 'The Contribution of Science and Technological Education to Citizens' Culture', Canadian Journal of Science, Mathematics and Technology Education 5(2), 253-263.

Gil- Pérez, D., Vilches, A., Edwards, M., Praia, J., Marques, L. \& Oliveira, T.: 2003, 'A Proposal to Enrich Teachers' Perception of the State of the World: first results', Environmental Education Research 9(1), 67-90.

Goldring, H. \& Osborne, J.: 1994, 'Students Difficulties with Energy and Related Concepts', Physics Education 29, 26-31.

Harman, P.M.: 1982, Energy, Force and Matter. The conceptual Development of NineteenthCentury Physics, Cambridge University Press, Cambridge.

Hashweh, M.Z.: 1986, 'Towards an Explanation of Conceptual Change', European Journal of Science Education 8(3), 229-249.

Hicks, N.: 1983, 'Energy is the Capacity to do Work - or is it?', The Physics Teacher 21, $529-530$.

Hodson, D.: 1992, 'In Search of a Meaningful Relationship: An Exploration of Some Issues Relating to Integration in Science and Science Education', International Journal of Science Education 14(5), 541-566.

Kaper, W.H. \& Goedhart, M.J.: 2002, 'Forms of Energy, an Intermediary Language on the Road to Thermodynamics? Part I', International Journal of Science Education 24(1), 81-95.

Kemp, H.R.: 1984, 'The Concept of Energy without Heat and Work', Physics Education 19(5), 234-240.

Koliopoulos, D. \& Ravanis, K.: 1998, 'L'ensegnement de l'energie au collège vu par les enseignants: Grille d'analyse de leurs conceptions', Aster 26, 165-182.

Kuhn, T.S.: 1977, The Essential Tension, The University of Chicago Press, Chicago, IL. 
Leff, H.S. \& Mallinckrodt, A.J.: 1993, 'Stopping Objects with Zero External Work: Mechanics Meets Thermodynamics', American Journal of Physics 61(2), 121-127.

Lehrman, R.: 1973, 'Energy is not the Ability to do Work', The Physics Teacher 11, 15-18. Mallinckrodt, A.J. \& Leff, H.S.: 1992, 'All about Work', American Journal of Physics 60(4), 356-365.

Matthews, M.R.: 1991, 'Un lugar para la historia y la filosofía en la enseñanza de las Ciencias', Comunicación, Lenguaje y Educación 11(12), 141-155.

Maxwell, J.C.: 1877, Matter and Motion, Society for Promoting Christian Knowledge, London[Reedited in 1991, Dover, New York].

McClelland, G.: 1989, 'Energy in School Science', Physics Education 24, 162-164.

McDermott, L.C.: 1993, 'How we Teach and How Students Learn: A Mismatch?', American Journal of Science 61, 295-298.

Morin, E.: 1999, Les set savoirs nécessaires à l'éducation du futur, UNESCO, Paris.

National Research Council: 1996, National Science Education Standards, National Academy Press, Washington, DC.

Nicholls, G. \& Ogborn, J.: 1993, 'Dimensions of Children's Conceptions of Energy', International Journal of Science Education 15, 73-81.

Ogborn, J.: 1986, 'Energy and Fuel - The Meaning of 'the go of things', in Driver R. \& Millar R. (eds) Energy Matters, University of Leeds, Leeds, pp. 59-66.

Ogborn, J.: 1990, 'Energy, Change, Difference and Danger', School Science Review 72(259), $81-85$.

Otero, J.: 1985, 'Assimilation Problems in Traditional Representation of Scientific Knowledge', European Journal of Science Education 7(4), 361-369.

Pfundt, H. \& Duit, R.: 1998, Bibliography of Students' Alternative Frameworks in Science Education, IPN, Kiel, Germany.

Pintó, R.: 1991, Algunos Conceptos implicitos en la Primera y Segunda leyes de la Termodinámica: una aportación al estudio de las dificultades de su aprendizaje, Universitat Autònoma de Barcelona, SpainPhD Thesis.

Posner, G.J., Strike, K.A., Hewson, P.W. \& Gertzog, W.A.: 1982, 'Accommodation of a Scientific Conception: Toward a Theory of Conceptual Change', Science Education 66(2), 211-227.

Prideaux, N.: 1995, 'Different Approaches to the Teaching of the Energy Concept', School Science Review 77, 49-57.

Resnick, R., Halliday, D. \& Krane, K.S.: 1992, Physics, Vol. 1, 4th edn, John Wiley \& Sons, Inc, New York.

Rogers, E.: 1965, Physics for the Inquiring Mind, Princeton University Press, Princeton, NJ.

Sexl, R.U.: 1981, 'Some Observations Concerning the Teaching of the Energy Concept', European Journal of Science Education 3(3), 285-289.

Shadmi, Y.: 1984, 'An outline of a mechanics course based on the Israeli junior High School Physics Curriculum', in Science Teaching In Israel: Origins, Development and Achievements, Jerusalem.

Sherwood, B.A.: 1983, 'Pseudowork and Real Work', American Journal of Physics 51(7), $597-602$.

Sherwood, B.A. \& Bernard, W.H.: 1984, 'Work and Heat Transfer in the Presence of Sliding Friction', American Journal of Physics 52(11), 1001-1007.

Shuell, T.J.: 1987, 'Cognitive Psychology and Conceptual Change: Implications for Teaching Science', Science Education 71(2), 239-250.

Solbes, J. \& Vilches, A.: 1997, 'STS Interactions and the Teaching of Physics and Chemistry', Science Education 81(4), 377-386. 
Solomon, J.: 1983, 'Learning About Energy: How Pupils Think in Two Domains', European Journal of Science Education 5, 49-59.

Solomon, J.: 1985, 'Teaching the Conservation of Energy', Physics Education 20, 165-170.

Stinner, A.: 1995, 'Contextual Settings, Science Stories, and Large Context Problems: Toward a more Humanistic Science Education', Science Education 79(5), 555-581.

Tarsitani, C. \& Vicentini, M.: 1991, Calore, energia, entropía, Ed. Franco Angeli Milán.

Tobin, K., Tippins, D. \& Gallard, A.J.: 1994, 'Research on Instructional Strategies for Teaching Science', in Gabel D.L. (ed) Handbook of Research on Science Teaching and Learning, MacMillan, New York.

Trumper, R.: 1990, 'Being Constructive: An Alternative Approach to the Teaching of the Energy Concept, Part one', International Journal of Science Education 12, 343-354.

Trumper, R.: 1991, 'Being Constructive. An Alternative Approach to the Teaching of the Energy Concept. Part two', International Journal of Science Education 13, 1-10.

Trumper, R.: 1993, 'Children's Energy Concepts', International Journal of Science Education 15, 139-148.

Trumper, R.: 1997, 'Applying Conceptual Conflict Strategies in the Learning of the Energy Concept', Research in Science \& Technological Education 15(1), 5-18.

Van Heuvelen, A. \& Zou, X.: 2001, 'Multiple Representations of Work-energy Processes', American Journal of Physics 69(2), 184-194.

Van Huis, C. \& Vanden Berg, E.: 1993, 'Teaching Energy: A Systems Approach', Physics Education 28, 146-153.

Van Roon, P.H., Van Sprang, H.F. \& Verdong, E.: 1994, “Work' and 'Heat': On a Road Towards Thermodynamics', International Journal of Science Education 16(2), 131-144.

Vilches, A. \& Gil-Pérez, D.: 2003, Construyamos un futuro sostenible: Diálogos de supervivencia, Cambridge University Press, Madrid.

Warren, J.W.: 1982, 'The Nature of Energy', European Journal of Science Education 4((3), 295-297.

Watts, D.M.: 1983, 'Some Alternative Views of Energy', Physics Education 18, 213-217.

White, T.R. \& Gunstone, F.R.: 1989, 'Metalearning and Conceptual Change', International Journal Science Education 11, 577-586. 